Tourism 2009, 19/1-2

\author{
Myriam Jansen-Verbeke \\ University of Leuven \\ Geo-Institute \\ Celestijnenlaan 200E, B3001 Leuven - Belgium \\ jansen.verbeke@skynet.be
}

\title{
THE TERRITORIALITY PARADIGM IN CULTURAL TOURISM
}

\begin{abstract}
A typical geographers' approach to tourism is to emphasise the analysis of spatial flows and space uses and the synthesis of territorial coherence between people, place and product. The renewed interest in the territorial aspects of tourism can be seen as a response to globalisation on the one hand and the search for unique, authentic and grass-rooted experience on the other. In recent tourism studies the focus and methods shift from a description of patterns to the analysis of processes of change that are induced by tourism (touristification). Understanding the forces that are transforming cultural landscapes (urban and rural) into tourismscapes is a crucial condition for visionary planning and responsible management of regions and places. Some reflections on the future research agenda in geo-tourism will be included.
\end{abstract}

Keywords: cultural tourism, territorial coherence, impact studies, touristification, cultural landscapes.

'The mobilization of cultural assets and activities
for developing tourism has emerged
as both evident and controversial.' X. GREFFE (2008)

\section{INTRODUCTION}

The growing interest in territorial expressions of history, habitat and heritage is in line with the current call for cultural identity of regions and communities. In the context of tourism as a global phenomenon and a globalising power, there is indeed an increased quest for regional differentiation, for images of unique landscapes, iconic cityand landscapes and localised narratives. There are plenty of examples of cultural resources now becoming driving forces in the process of creating and expanding the regional and local 'Tourist Opportunity Spectrum' (BUTLER \& WOLDBROOTZ 1991). Looking at space and territorial characteristics as a key factor for the development of tourism is not very original. What is new is the analytical approach to the concept of 'territoriality'. This refers to a persistent attachment of people, culture and ways of life to a specific territory, sometimes within clear geographical boundaries, sometimes referring to more diffuse patterns. The territorial linkages of human settlement with landscapes and regions are shaped through the interaction between nature and human activity, and marked by a unique history and habitat. The concept 'territorium' was introduced in the early geographical studies of Alexander von
Humbolt (1769-1859, Germany) and Vidal de la Blache (1845-1918, France). This is in many ways the basis of what was later developed as regional geography. Their views on the linkages between people, place and environment tended to be classified as a form of environmental determinism. Obviously, this interpretation did not survive in modern times, when humans were seen as masters of their environment and way of life.

Nowadays notions of territory, habitat, local history and folklore are loaded with new values. Typical regional patterns and the traditional coherence of cultural resources are valorised as 'heritage' as will be illustrated here. The recognition of cultural landscapes as carriers of heritage (elements and systems) opens new perspectives for rural areas and communities and for agricultural heritage systems in particular. Above all there are new challenges to (re)connect tangible and intangible cultural heritage resources in the process of the revalorisation of territories and reviving regional identities. Cultural landscapes are seen as cultural properties representing the combination of the works of nature and of man. Marked by history and way of life, cultural landscapes illustrate the evolution of 
human society and settlement over time. In addition they hold the imprints of physical constraints and/or opportunities presented by the natural environment and are shaped by successive social, economic and cultural forces, both external and internal (UNESCO 2007). When introducing cultural landscapes on the UNESCO agenda as a spatial category of heritage, a distinction was made between:

1. Landscape designed and created intentionally by man - including garden and parkland landscapes constructed for aesthetic reasons which are often (but not always) associated with religious or other monumental buildings and ensembles.

2. Organically evolved landscape - resulting from an initial social, economic, administrative, and/or religious imperative, which has developed its present form by association with, and in response to, its natural environment. Such landscapes reflect the process of evolution in their form and component features.

3. Associative cultural landscape - such landscapes have been inscribed on the World Heritage List, justified by virtue of powerful religious, artistic or cultural associations.

From a cultural tourism perspective there is a renewed interest in the three types of cultural landscapes that can be traced both at the macro level of symbolic landscapes, and recently at the micro level looking at the transformation into specific types of 'new' landscapes. Analyzing and managing transformation implies a deeper understanding of the factors of change and their impact on landscapes or its components. The need to analyse the irreversible and hybrid impact of tourism on the environment is an emerging challenge for researchers and planners (AGARWAL, BALL, SHAW \& WILLIAMS 2000). The introduction and implementation of a system approach, based on visions about interaction and interdependency, have a high priority and are driven by the current search for new management tools and monitoring systems. Although geographers can be seen as founders of the tourism perspective on landscapes, creators of (tourist) maps and often the best writers of travel guides, the challenges of managing tourism and its impact now require interdisciplinary knowledge about a complex phenomenon. Within the wide spectrum of social, economic and cultural changes, we focus on the conditions for an interactive process between cultural resources and tourism development, assuming that this synergy has a positive impact and contributes to a sustainable development of the territory. The rediscovery and growing awareness of territorial resources and identities is definitely related to the current regionalisation movement in the new Europe (HALL, SMITH \& MARCISZEWSKA 2006). The region as a territorial entity, and also as an organisational unit in tourism development and destination marketing, is an old but recently revalorised strategy (ESPON, 2006, RIEUCAU \& LAGEISTE, 2006, GRAVARI-BARBAS \& VIOLIER 2003). Regions are branded and icons are strategically selected in order to attract tourism. For instance, the association of cultural landscapes with typical and traditional territorial products, and the protection of (agricultural) product brands, are reinforced by European legislation (RUSSO \& SEGRE 2009). Although the main objective is registration and protecttion of ownership, this policy opens new perspectives for the branding of territories based on the mix and interaction of their tangible and intangible heritage (SANTAGATA, RUSSO \& SEGRE 2008, JANSEN-VERBEKE 2009). This reinforces the current 'back to the roots' movement. The revalorisation of the past is definitely inspired by the search for 'unique selling propositions' (USP) for the marketing of destinations, regions, attractions, and events.

\section{TERRITORIAL COHESION: AN ANALYTICAL APPROACH}

The objective of this section is to comment upon some analytical tools for the study of territoriality and territorial heritage systems, assuming the growing relevance of these concepts for the future of cultural tourism. The process of 'touristification' cannot be fully understood without scanning the multi-dimensional context and referring to the territoriality paradigm in the development of tourism. This implies looking at heritage in its biotope or habitat. Assessing the role of cultural assets in the process of territorial cohesion and identity building has definitely become a major challenge. This does not represent exactly a return to the regional geography of the past, but an attempt to revive the territorial coherence between a place and its people, their history, habitat, and heritage in a globalised world and cosmopolitan community.

For the purpose of empirical analyses of cultural resources, a framework was designed including various components of territorial cohesion (JANSENVERBEKE 2007). The potential for tourism development is assessed in terms of hardware, software and orgware, and shareware. A most critical aspect in the realization of a coherent tourism destination is the networking (physical, functional and organizational) to be established at different scales (Fig. 1). The model involves a comprehensive analysis and maping of cultural resources and tourism infrastructure, and implies a multidimensional approach in order to assess: 
- the quality and quantity of the hardware - tangible heritage (icons, landmarks, regional tourismscapes, etc.) and the physical infrastructure in the region;

- the strength and weaknesses of the software: images, narratives, intangible heritage (traditions, music, food, handicrafts, etc) and the capacity to valorize these in the cultural tourism market (JANSENVERBEKE 2009);

- the perspectives and constraints of the current orgware: type and power of organizations, participation of different stakeholders, inclusion and exclusion of community stakes.

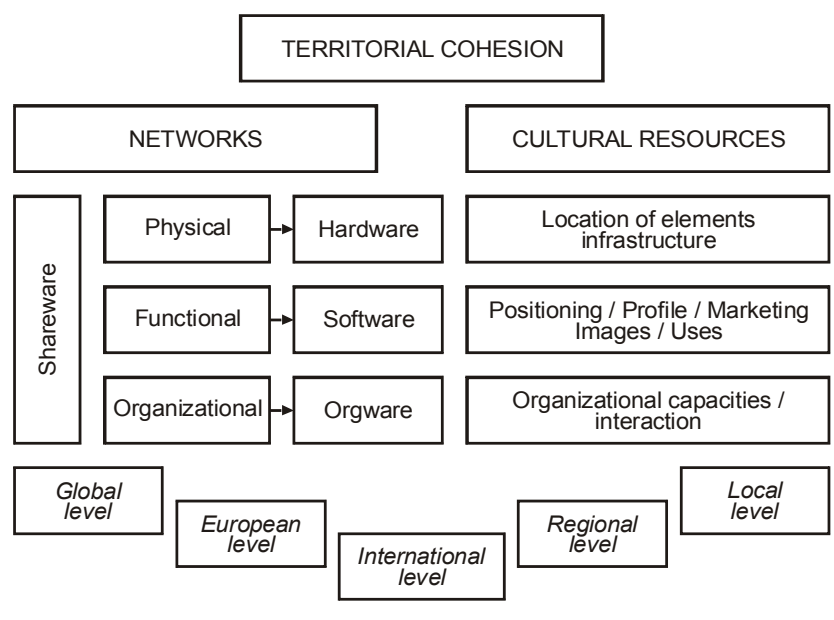

Fig. 1. Territorial Cohesion: an analytical model (s o u r c e: ESPON 2006, adapted by author, 2007)

The application of this model on a regional and local level allows the identification of potential and of weak points in developing a regional cultural identity and tourism destination. The development and strengthening of networks requires a three-fold set of strategies:

- Physical networks are important for route and corridor development; linear clustering of economic activities induced by or supported by tourism routes, tracks, and promoted as such for tourism (ROMAGOSA \& Russo 2008). Location choices for new developments can be tested in this way.

- Functional networks link the local offer of cultural tourism services and products with global markets. This implies innovative strategies, the production of interactive audiovisual material, in order to penetrate the mental map of tourism organizations and tourists.

- Organizational networks are needed to realize new initiatives, and to develop visionary and inspired tourism policies. Priority should be given to bottomup initiatives, conceived and supported by different community groups, location-based tourist services, platforms for the launching of new ideas on tourist products, events, etc.;

In fact, this interpretation of territorial cohesion advances the basis for an integrated planning approach to tourism destinations. The conditions for networking clearly link the local offer for cultural tourism with regional and global markets. As such the model can be both an analytical tool to assess tourism potential and an incentive for creative strategies.

\section{TOURISM IMPACT STUDIES: AN INTEGRATING FRAMEWORK}

The interest of regional tourism studies is tending to shift from an analysis of tourism potential and development plans, to impact assessment studies. Apparently this type of legitimation is expected in the context of sustainable development and to generate support for any new project or activity in a particular area. The territorial approach proves to be most relevant for the exercise of impact assessment or impact simulation. The model (Fig. 2) below can be applied to a multi-dimensional analysis of a range of indicators and applicable to study areas at different scales, however very much dependent on the availability of data.

Gradually the research focus concentrates on transformation processes induced by tourism. The multi-dimensional impact of tourism on the natural and morphological characteristics, on social and political relationships, on economic structures and functional profiles can be assessed through a number of selected indicators. Obviously, in order to study the dynamics of change, the complexity of the tourism system needs to be well understood. When scanning the flow of recent publications on tourism we could conclude that interest in the spatial impact of tourism on territories is remarkably low when compared to the economic or business, management and marketing issues being studied and reported (LEW, Hall \& WiLliams 2006). Our point is that the territorial approach allows the inclusion and analysis of various components and the synthesis of their interactions in a comprehensive way. The model includes indicators of impact which are relevant for the monitoring of tourism-induced changes (touristification) in a specific area. As such this can be an efficient management tool in the perspective of sustainable development. Policy makers share a contagious ambition to manage and control the processes of change induced by tourism in their respective territories. 


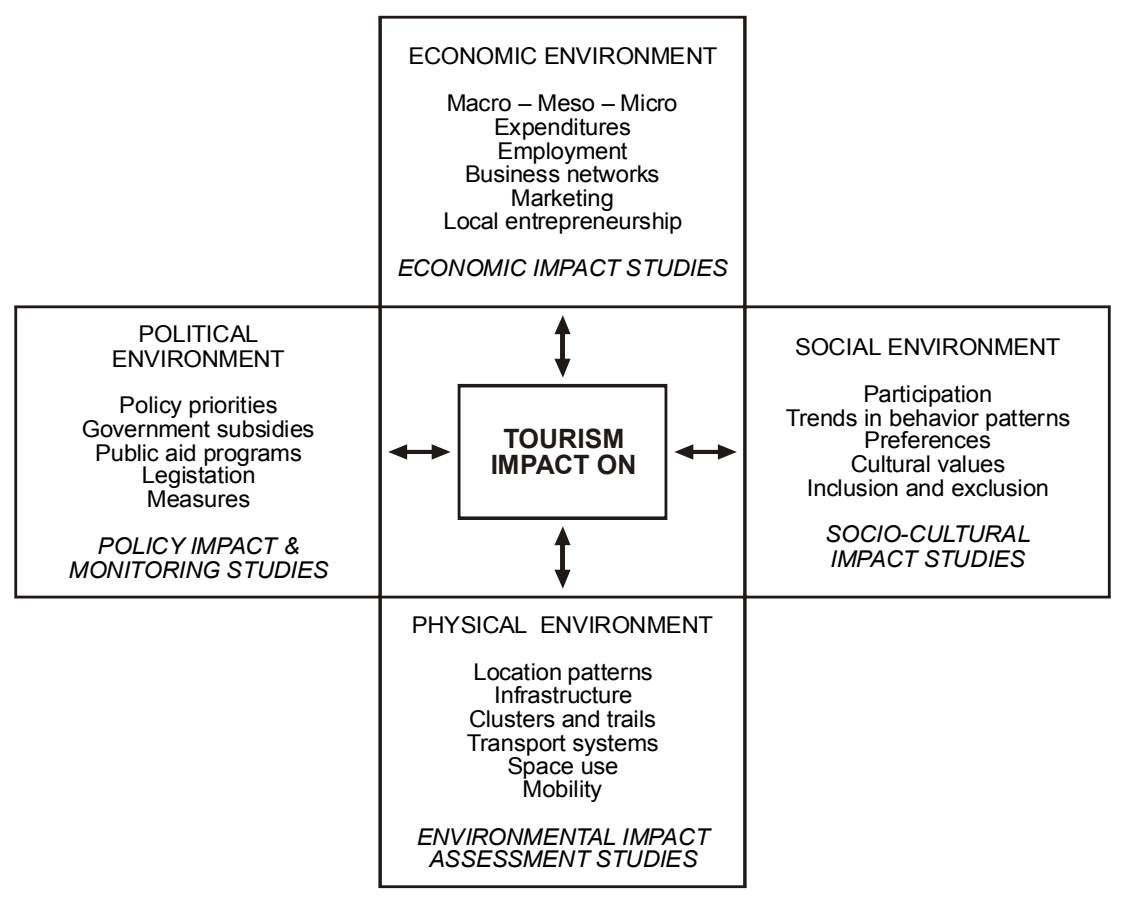

Fig. 2. Tourism impact studies: an integrating framework (s o u r c e: JANSEN-VERBEKE, 2008)

This can only become a realistic proposition when there is agreement about relevant indicators of change and, above all, tools to measure the various aspects of spatial impact. Again the territoriality paradigm is important in this search for a wellbalanced and integrated tourism development model. The spatial perspective in the kaleidoscope of multi-disciplinary research has its advantages. The technological tools to track changes in land-use patterns are now available; the problem rather resides in the interpretation of the driving forces in spatial transformation and the social understanding of changing patterns of space use (JANSEN-VERBEKE 2007). The process of 'tourismification' generates new dynamics which also affect the immediate surroundings. In fact, the boundaries of territories become irrelevant, but remain useful for spatial analysis purposes.

\section{TOURISTIFICATION OF CULTURAL LANDSCAPES}

In the context of a European project on 'The role and spatial effects of cultural heritage and identity' (ESPON, 2006), a range of data on cultural resources and activities was registered in 25 European countries. With a view to drawing a map of cultural tourism, specific data was collected to indicate the density of Cultural heritage assets in a territory (using NUTS II level). It is well-known that data registration on cultural parameters is much less advanced than in other sectors of territorial studies. The limitations for comparative or longitudinal studies are considerable. As a consequence, the construction of a typology of cultural landscapes can hardly be based on valid data. Mapping regional differences in Europe using a selection of parameters, eventually indicated two important dimensions in tourism dynamics (Fig. 3). Two specific dimensions have been tested in the European study on spatial aspects of cultural resources in Europe (ESPON 2006): population density (degree of urbanisation) and density of tangible heritage assets. To some extent, the metamorphosis of cultural landscapes induced by tourism can be explained by the interaction of these two dimensions.

The first dimension (Fig. 3), the degree of urbanization - by definition related to population density is most relevant to the type of tourism and leisure landscape that is emerging. Leisure destinations for urban dwellers, with a typical centrifugal flow of movements, differ significantly from centripetal flows to urban destinations for city trips, cultural activities, shopping. Distinct spatial categories, such as the rural countryside, the peri-urban leisure and sport zones, and multi-functional urban areas, are in fact complementary in their social function for visitors and residents. Anyhow, the sharp dividing lines between work and leisure time, between travel 


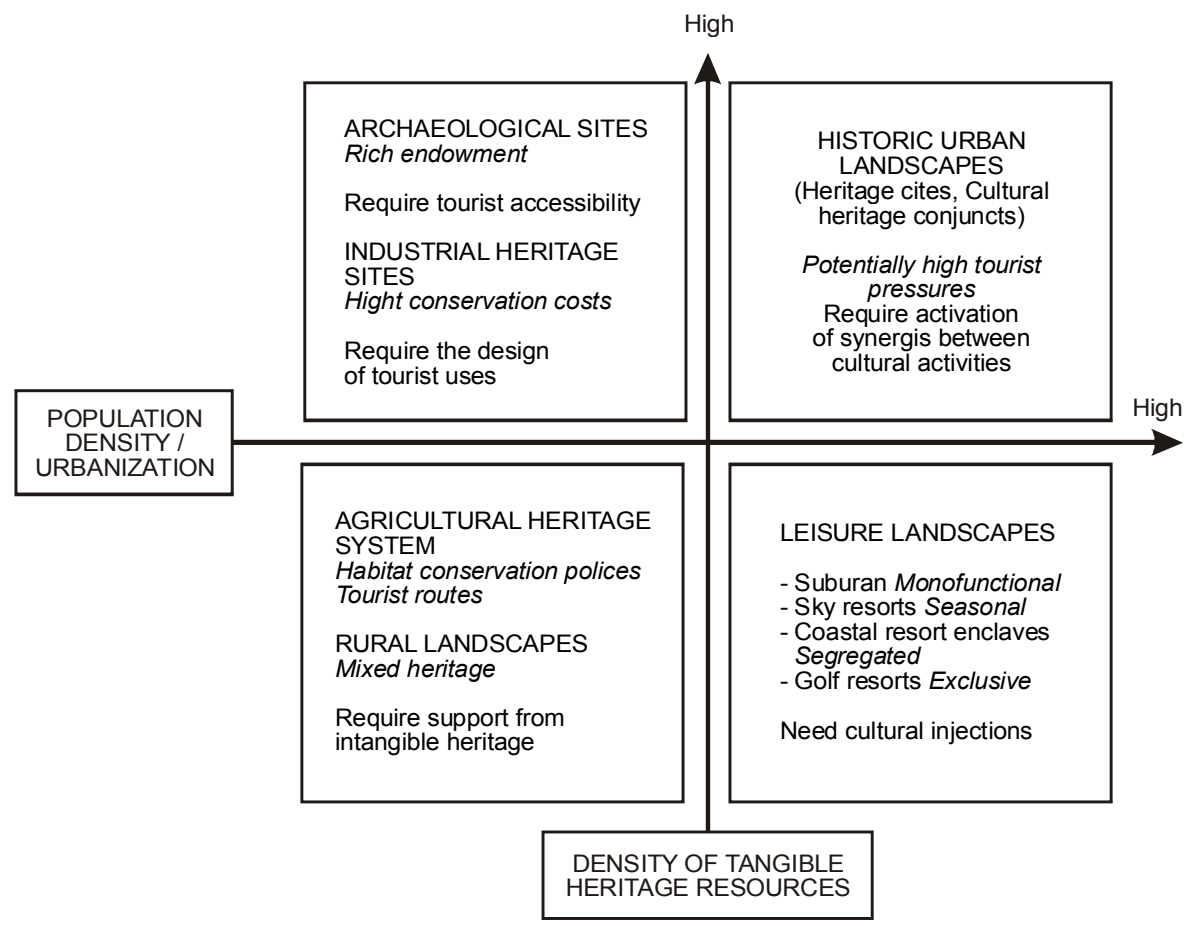

Fig. 3. Types of cultural landscapes for tourism (s o u r c e: author, based on ESPON 1.3.3; 2006, p. 164)

for work and for pleasure, cultural activities and entertainment are fading away (METZ 2002). This social phenomenon also affects the spatial structure and functional mix in leisure and tourism environments.

Nevertheless in many regions, the contrast between densely-populated urban areas and the rural, agricultural or natural countryside in terms of tourism intensity, space claims and uses, perception and experiences, remains considerable. Clearly the tourist opportunity spectrum in urban and in rural areas differs, so do the motivations and activities of visitors.

There are multiple examples of territories where urbanization, modern agricultural practices and new concepts of leisure landscapes (holiday camps, wellness resorts, ski stations, etc) are a threat for the conservation of valuable natural and cultural landscapes. The shift from traditional agriculture to agribusiness, from extensive recreation in the countryside to designed leisure areas and sign-posted tourist routes, the huge investments made to facilitate high accessibility for different travel modes, all have a price. Conservation policies for cultural heritage are not often compatible with such development goals (HOWARD 2004, BRIEDENHANN \& WICKENS 2004).

The second dimension (Fig. 3), the cultural endowment of the territory or the density of tangible cultural heritage elements has proven to be highly relevant when assessing the tourism potential of cultural landscapes. For instance, when the parameter is restricted to the presence of tangible cultural heritage elements such as museums and monuments exclusively, it is possible to construct a density index. This allows the distinguishing, in a quantitative way, of regions with high or low densities of tangible heritage elements (ESPON 2006, pp. 102-3). Surely, the cultural tourism potential of a territory does not depend on the quantity of heritage sites, buildings and artefacts only, but most of all on the quality of conservation, and the creativity of landscaping to maintain the historical coherence between buildings, landscapes and artefacts. In addition the richness of the territorial endowment can be supported significantly by specific expressions or interactions with intangible heritage assets. Numbers of heritage buildings, sites, artefacts, elements, their scale and density indices, are seen as 'hard' indicators. However the territorial coherence of various cultural resources is an even more critical issue.

The range of criteria to assess the tourism potential of cultural resources and sites remains a point of discussion (JANSEN-VERBEKE, PRIESTLEY \& RUSSO 2008). The ongoing search for quantitative criteria is very understandable, particularly in the current comparative situation and competitive marketing of many regions in the enlarged Europe (HALl, SMITH \& MARCISZEWSKA 2006). The typology 
of cultural landscapes and their orientation to tourism (Fig. 3) is not a static model, but a framework to distinguish different key issues in the process of tourism development. The orientation of cultural landscapes to tourism depends mainly on three factors: firstly protection and conservation policies regarding tangible heritage, secondly the skills and creativity in transforming cultural resources into drivers of a cultural economy, while the third and most crucial factor is the capacity to integrate cultural assets in a dynamic and innovative tourism destination development.

Understanding the dynamics of cultural landscapes requires much more than mapping urbanisation indices and cultural heritage density scores. Some landscapes go through a real morphological transformation to become planned leisure landscapes, whereas other agricultural and rural landscapes have functionally developed into destinations for extensive cultural tourism (JANSEN-VERBEKE, PRIESTLEY \& RUSSO 2008). The dilemma between freezing landscapes of the past (for example rural hamlets, old fishing villages, agricultural habitat systems, traditional handicraft places, pre-industrial working sites, etc.), and the injection of new economic activities, cannot be easily solved, nor is there a universal best practice model of development. Historic cultural landscapes are under pressure, particularly in densely populated areas. The spatial clustering of cultural heritage elements in urban areas is inherent to the history and genesis of most cities. A concentration of historical buildings, museums and monuments belongs to a typical cityscape. Moreover, cultural events, rooted in history and local traditions, tend to follow a similar spatial distribution pattern (STEINECKE 2007). These are the favourable conditions for the creation of a sustainable and inclusive 'tourismscape' (VAN DER DUIM 2007).

\section{LEISURE LANDSCAPES OF THE $21^{\text {ST }}$ CENTURY}

Within the typology of cultural landscapes (Fig. 3) the creation of new leisure landscapes is probably one of the most challenging topics: the dilemma of 'planning' landscapes to meet the leisure demands of the future. Some territories are advantaged through the presence of a rich heritage (tangible and intangible). Many historical cities belong to that category. However, not all urban areas have inherited a rich patrimony on which to build a cultural economy in the $21^{\text {st }}$ century. Apparently tourism researchers have paid much less attention to under-endowed urban areas or to vast recently urbanized areas with few or no historical landmarks.
The creation of new leisure landscapes to benefit from the expanding leisure economy is top of many developers' agenda. The trick seems to be the creation of new tourism magnets in the urban periphery with eye-catching modern architecture for museums, concert halls, convention centres, multi-functional leisure palaces, hotels, theme parks, etc. Successful suburban leisure clusters are now becoming part of the urban dynamics in the tourism market. Designed as leisure landscapes for the urban population, these peri-urban destinations gradually appear on the mental map of tourism business and the tourist. This spatial concept is a new category in the field of environmental planning. So far the leisure function was never considered to be dominant or manifest, but social trends and new economic realities are rapidly changing the map (DE HAAN \& VAN DER DUIM 2008).

Many leisure landscapes have a poor cultural endowment being designed as mono-functional residential areas, many of them as resorts for seasonal use by tourists and second homeowners. This manifest invasion of tourism functions into rural, coastal and natural landscapes is irreversibly changing their morphology, affecting traditional ways of life. In some regions, the spatial claims and impacts of ski, golf and coastal resorts are considerable. The scenario of almost mono-functional tourism landscapes is expanding universally with only occasional touches of vernacular architecture referring to the place or the region, or as icons of local culture and territorial traditions. In many regions this type of urbanised area with a low population density, and seasonal occupancy, has little to offer to cultural tourism. A low density of cultural assets characterizes newlybuilt tourist villages, ski resorts, seaside developments and golf destinations. As these destinations mature they are gradually looking for more social coherence and cultural vitality; promoting art galleries, festival shopping, events, summer schools for special interest groups, sport academies, etc. These 21st century tourism urbanization areas, sometimes indicated as exclusive tourist bubbles are in fact the expression of a new type of cultural landscape, 'The habitat of a new leisure society' (AITCHISON, MACLEOD \& SHAW 2000).

\section{CONCLUSION}

New topics and paradigms are challenging innovation in the tourism research agenda, many of which require a multi-disciplinary approach. Developing tools to measure and monitor the impact of various forms of tourism, and in different environmental settings, has a high priority nowadays. Cultural 
tourism was initially studied as a global movement with an expanding market, is now analysed at the micro-level of territorial embedding, at the mesolevel of networks and at the micro-level of individual experiences.

More than ever there is a need to integrate tourism to the existing landscape, to be included in the cultural environment and in the global framework of economic forces. This implies a growing interdependency of disciplines, skills and knowledge networks (VAN DER DUIM 2007). The capacities required for the implementation of sustainable models and practices of integrated destination planning, not only include a theoretical knowledge of patterns and processes, but above all creative and synthetic views of future developments (RICHARDS \& WILSON 2006). Tourism no longer deals with a dichotomy of offer and demand, but with finding harmony or equilibrium between form and function, place and people and the capacity to develop both. Perhaps a visionary agenda is needed to anticipate 'post tourism syndromes' and the impact on places and people and on quality of life. The future scenario of ever-expanding tourism travel and a continued fever of building new resorts is frightening, to say the least. Dissociation between project developers, real estate business, environmental managers, cultural, leisure and tourism experts, and - even worse - with the educational foundations of tourism management, is navigating without a compass.

\section{BIBLIOGRAPHY}

AgarWAL, S, BALL, R., SHAW, G., Williams, A., 2000, The geography of tourism production: uneven disciplinary development?, Tourism Geographies 2(3), pp. 241-263.

AITCHISON, C., MACLEOD, N. E., SHAW, S. J., 2000, Leisure and tourism landscapes: social and cultural geographies, Routledge, London.

BRIEDENHANN, J., WICKENS, E., 2004, Tourism routes as tool for economic development of rural areas: Vibrant hope or impossible dream?, Tourism Management, 25(1), pp. 71-79.

Butler, R ., WoldBrootz, L., 1991, A New Planning Tool: Tourist Opportunity Spectrum, The Journal of Tourism Studies 2(1), pp. 2-14.
BUTLER, R.W. (ed.), 2006, The tourism area life cycle. Vol. 2: Conceptual and theoretical issues, Channel View Publication, Clevedon, UK.

DE HAAN, H., VAN DER DUIM, R. (eds), 2008, Landscape, Leisure and Tourism, Eburo: Delft.

ESPON, 2006, The role and spatial effects of cultural heritage and identity (2004-2006), Final Report Project 1.3.3. EU Luxemburg.

GRAVARI-BARBAS, M. \& P. VIOLIER (eds), 2003, Lieux de culture et culture des lieux; production(s) culturele(s) locale(s) et émergence des lieux: dynamiques, acteurs, enjeux, PUR, Rennes.

HALL, D., SMITH, M., MARCISZEWSKA, B. (eds), 2006, Tourism in the New Europe. The Challenges and Opportunities of EU Enlargement, CAB International, Wallingford.

HOWARD, P. 2004, Spatial planning for landscape: Managing the pitfalls, Landscape Research 29(4), pp. 423-434.

JANSEN-VERBEKE, M., 2007, Cultural resources and the tourismification of territories, Acta Turistica Nova, 1(1), pp. 21-41.

JANSEN-VerbeKe, M., PRIESTley G.K., Russo, A.P. (eds), 2008, Cultural Resources for Tourism: Patterns, Process and Policies, Nova Science, New York.

JANSEN- VERBEKE, M., 2008, A Geographer's Gaze at Tourism, Documents d'Anàlisi Geogràfica, 52 (2), pp. 15-29.

JANSEN-VERBEKE, M., 2009, Territorial embedding of intangible heritage and cultural tourism, [in:] Sharing Cultures- International Conference in Intangible Heritage - Conference Proceedings, Green Line Institute - Azores - Portugal (in press).

LEW, A., HALl, M., TimOTHY, D., 2008, World Geography of Travel and Tourism - A regional approach, Butterworth Heinemann Oxford.

LeW, A, Hall, M., Williams, A. (eds), 2004, A companion to tourism, Blackwell Publishing, Oxford.

Metz, T. 2002, Fun! Leisure and landscape, NAI Publishers, Rotterdam.

RICHARDS, G, WILSON, J., 2006, Developing creativity in tourist experiences: A solution to serial reproduction of culture?, Tourism Management, 27, pp. 1209-1223.

RIEUCAU J., LAGEISTE, J. (eds), 2006, L'empreinte du tourisme; Contribution à l'identité du fait touristiques, L'Harmattan, Paris.

RomagosA, F., RUSSO, A.P. 2008, The advantages of sharing: A case study of the Jewish Heritage Network in Spain, [in:] Jansen-Verbeke, M., Priestley G.K., Russo, A.P. (eds), 2008, Cultural Resources for Tourism: Patterns, Process and Policies, Nova Science, New York, pp. 59-78.

RUSSO, A.P., SEGRE, G., 2009, Destinations and property regimes: an exploration, (accepted for publication - March 2009) in Annals of Tourism Research.

SANTAGATA, W., RUSSO, A.P., SEgRE, G., 2008, Tourist quality labels: An incentive for the sustainable development of creative clusters as tourist attractions? [in:] Richard, G. Wilson, J. (eds), Tourism, Creativity and Development, ATLAS, Arnhem.

STEINECKE, A., 2007, Kulturtourismus, Oldenbourg Verlag, München -Wien.

VAN DER DUIM, R. 2007, Tourismscapes: An actor-network perspective, Annals of Tourism Research, 34(4), pp. 961-976. 